\title{
SPRAWOZDANIE \\ Z DZIAŁALNOŚCI FUNDACJI GENERAŁ ELŻBIETY ZAWACKIEJ. ARCHIWUM I MUZEUM POMORSKIE ARMII KRAJOWEJ ORAZ WOJSKOWEJ SŁUŻBY POLEK W TORUNIU ZA ROK 2015
}

\section{DANE ORGANIZACJI:}

1. Nazwa fundacji, jej siedziba i adres:

Fundacja Generał Elżbiety Zawackiej. Archiwum i Muzeum Pomorskie Armii

Krajowej oraz Wojskowej Służby Polek, ul. Podmurna 93, 87-100 Toruń

2. Data wpisu w Krajowy Rejestr Sądowy i numer KRS:

Data rejestracji: 06.09.2001, nr KRS 0000041692

\section{REGON: 870502736}

4. Zarząd fundacji - praca społeczna

1. Prezes: Dorota Zawacka-Wakarecy

2. Wiceprezes: Katarzyna Minczykowska-Targowska

3. Sekretarz: Dorota Kromp

\section{Rada Fundacji:}

1. Przewodniczący: Jan Wyrowiński (mgr inż., Toruń)

2. Józef Borzyszkowski (prof. dr hab., Gdańsk)

3. Bogdan Chrzanowski (prof. dr hab., Gdańsk)

4. Andrzej Gąsiorowski (prof. dr hab., Gdańsk)

5. Mirosław Golon (dr hab., prof. UMK)

6. Grzegorz Górski (prof. dr hab., Lublin)

7. Sylwia Grochowina (dr hab., Toruń) - od marca 2015 r.

8. Andrzej Kola (prof. dr hab., Toruń) - od marca 2015 r.

9. Waldemar Rezmer (prof. dr hab., Toruń)

10. Jan Sziling (prof. dr hab., Toruń)

11. Andrzej Tomczak (prof. dr hab., Torun)

12.Zbigniew Wojtczak (prof. dr hab., Toruń)

13. Krystyna Wojtowicz (mgr, Kraków)

\section{Komisja Rewizyjna:}

1. Przewodnicząca: Anna Kłobukowska (Toruń) - od marca 2015 r.

2. Jarosław Kłaczkow (prof. dr hab., Toruń)

3. Maria Ciesielska (Toruń) 


\section{Pracownicy i współpracownicy (um. cywilno-prawne):}

W roku sprawozdawczym Fundacja zatrudniała 64 osoby na um. o dzieło/ zlecenie (w tym wystąpienia konferencyjne, autorstwo tekstów), w tym 2 osoby na um. o pracę:

1. Andrej Amons (konferencja; um. o dzieło)

2. Jarosław Bednarek (badania archeologiczne; um. o dzieło)

3. Maria Blomberg (wydawnictwo; um. o dzieło)

4. Wiesława Chwedoruk (konferencja; um. o dzieło)

5. Maria Ciesielska (dział: Archiwum Pomorskie - opracowywanie; um. o dzieło)

6. Bartosz Drzewiecki (wydawnictwo; um. o dzieło)

7. Zuzanna Filarska (grafik, wydawnictwa, konferencje; um. o dzieło)

8. Sławomir Frątczak (konferencja; um. o dzieło)

9. Andrzej Gąsiorowski (konferencja; um. o dzieło)

10. Marian Głosek (konferencja; um. o dzieło)

11. Tomasz Górzyński (mural; um. o dzieło)

12. Waldemar Grabowski (konferencja; um. o dzieło)

13. Marcin Gręzlikowski (mural; um. o dzieło)

14. Sylwia Grochowina (wydawnictwo; um. o dzieło)

15. Małgorzata Grupa (konferencja; um. o dzieło)

16. Ksawery Jasiak (konferencja; um. o dzieło)

17. Włodzimierz Jastrzębski (konferencja; um. o dzieło)

18. Damian Jędrzejewski (mural; um. o dzieło)

19. Andrzej Kola (konferencje; um. o dzieło)

20. Andrzej Korzybski (dział: Archiwum Pomorskie - digitalizacja; um. o dzieło)

21. Joanna Kozłowska (konferencja; um. o dzieło)

22. Dorota Kromp (wydawnictwa; um. o dzieło)

23. Adam Kuczyński (badania archeologiczne; um. o dzieło)

24. Agnieszka Łuczywek (sekretariat; dział Ikonografii - digitalizacja, mural, prelekcje; um. o dzieło, um. zlec.)

25. Anna Mikulska (działy: Archiwum WSK, Muzealia - udostępnianie, opracowywanie, digitalizacja; um. o dzieło)

26. Katarzyna Maniewska (konferencja; um. o dzieło)

27. Janusz Marszalec (konferencja; um. o dzieło)

28. Katarzyna Mazur (konferencja; um. o dzieło)

29. Anna Mikulska (dział: Archiwum WSK - opracowywanie, digitalizacja, prelekcje; wydawnictwo; um. o dzieło, um. zlec.)

30. Joanna Mikulska (dział: Ikonografii - digitalizacja; um. o dzieło)

31. Katarzyna Minczykowska-Targowska (digitalizacja, prelekcje, archiwizacja, wydaw-nictwo; konferencje; um. o dzieło, um. zlec.)

32. Joanna Morowiec (konferencja; um. o dzieło)

33. Łukasz Odrobiński (dział: Archiwum Pomorskie - digitalizacja; um. o dzieło)

34. Krzysztof Osiński (konferencja; um. o dzieło)

35. Marcin Owsiński (konferencja; um. o dzieło)

36. Alicja Paczoska-Hauke (konferencja; um. o dzieło)

37. Dominika Pasich (konferencja; um. o dzieło)

38. Krystyna Piórkowska (konferencja; um. o dzieło) 
39. Tymoteusz Pruchnik (konferencja; um. o dzieło)

40. Joanna Roftopolus (konferencja; um. o dzieło)

41. Teresa Rączka-Jezierska (konferencja; um. o dzieło)

42. Małgorzata Replińska (konferencja; um. o dzieło)

43. Dawid Rogoziński (dział: Archiwum Pomorskie - digitalizacja, udostępnianie; um. o dzieło, um. zlec.)

44. Barbara Rojek (dział: Archiwum WSK - digitalizacja, udostępnianie; um. o dzieło, um. zlec.)

45. Anna Rojewska (dział: Archiwum WSK - digitalizacja; um. o dzieło)

46. Ewa Rzeczkowska (konferencja; um. o dzieło)

47. Maciej Sadowski (konferencja; um. o dzieło)

48. Izabela Sariusz-Skąpska (konferencja; um. o dzieło)

49. Dominika Siemińska (badania archeologiczne, konferencje; um. o dzieło)

50. Michał Siemiński (badania archeologiczne; um. o dzieło)

51. Elżbieta Skerska (dział: Archiwum Pomorskie - opracowywanie, digitalizacja, prelek-cje, wydawnictwo; um. o dzieło, um. zlec.)

52. Remigiusz Stasiak (konferencje; um. o zlec.)

53. Jan Sziling (wydawnictwo, digitalizacja; um. o dzieło)

54. Wojciech Szreniawski (wydawnictwo; um. o dzieło)

55. Marek Szymaniak (konferencja; um. o dzieło)

56. Zofia Świtajska (dział: Biblioteka, um. zlec.)

57. Karol Wakarecy (digitalizacja; um. o dzieło)

58. Małgorzata Walczewska (sprzątanie; um. zlec.)

59. Wirginia Węglińska (konferencja; um. o dzieło)

60. Izabela Wilewska (sekretariat: um. o pracę; dział: Archiwum WSK - digitalizacja; um. o dzieło)

61. Artur Wodzyński (konferencja; um. o dzieło)

62. Agnieszka Zasada (dział: Archiwum WSK - digitalizacja; um. o dzieło)

63. Dorota Zawacka-Wakarecy (zarząd; um. zlec.)

64. Maciej Żuczkowski (konferencja; um. o dzieło)

\section{Stażyści, praktykanci, wolontariat:}

a) Studenckie praktyki studenckie odbyło 4 studentów UMK; jedna osoba odbywała staż.

b) Wolontariat:

1. Maria Ciesielska (dział: Archiwum Pomorskie 3-5 h/tydz.)

2. Regina Dąbkowska (sekretariat, dział: Muzealia; obsługa Kongresu)

3. Bartosz Kopczyński (obsługa Kongresu),

4. Weronika Kubiak (obsługa Kongresu),

5. Natalia Łata (obsługa Kongresu),

6. Krzysztof Maliszewski (obsługa Kongresu),

7. Katarzyna Masloch (sekretariat, digitalizacja, obsługa Kongresu),

8. Łukasz Odrobiński (dział: Archiwum Pomorskie),

9. Katarzyna Minczykowska-Targowska (kierownik Archiwum, wiceprezes zarządu, sekretarz Komitetu Redakcyjnego Biblioteki Fundacji),

10. Barbara Rojek (dział: Archiwum WSK), 
11. Jan Sziling (członek Komitetu Redakcyjnego),

12. Andrzej Tomczak (Przewodniczący Komitetu Redakcyjnego),

13. Dorota Zawacka-Wakarecy (Prezes Zarządu Fundacji oraz Przewodnicząca Memoriału)

- Członkowie Koła Przyjaciół Memoriału (do grona członków MGMW dołączyły 4 osoby, 11 osób zmarło, 4 osoby wykreślono z uwagi na brak kontaktu i zwroty poczty). Łącznie Memoriał skupia 251 osób, w tym ok. 15 pracuje bardzo aktywnie, inni współpracują spora-dycznie, a nieliczni wspierają Fundację finansowo.

\section{CELE I ZASADY DZIAŁANIA}

\section{Cele statutowe fundacji:}

Fundacja służy popieraniu badań:

- historii Armii Krajowej na Pomorzu, utrwalaniu i upowszechnianiu historii, tradycji i dziedzictwa ideowego Armii Krajowej;

- dziejów wojskowej służby Polek i upamiętnianiu tradycji tej służby.

\section{Cele swe Fundacja realizuje poprzez:}

- gromadzenie, opracowanie i udostępnianie nie stanowiących państwowego zasobu archiwalnego materiałów archiwalnych, dokumentacji i muzealiów dotyczących Armii Krajowej na Pomorzu oraz wojskowej służby Polek;

- gromadzenie publikacji dotyczących pomorskiej AK oraz wojskowej służby Polek;

- gromadzenie i opracowywanie wspomnień i relacji żołnierzy AK z Pomorza oraz Polek służących w wojsku;

- udostępnianie gromadzonych materiałów archiwalnych zainteresowanym, w szczególności historykom badającym dzieje AK na Pomorzu oraz dzieje wojskowej służby Polek;

- gromadzenie, opracowywanie i udostępnianie wszelkiego rodzaju pamiątek typu muzealnego po AK na Pomorzu i po wojskowej służbie Polek;

- gromadzenie i opracowywanie materiałów dotyczących działalności konspiratorów rodem z Pomorza w ogólnopolskich strukturach oraz materiałów dotyczących środowisk konspiracyjnych po roku 1945.

\section{CHARAKTERYSTYKA DZIAŁALNOŚCI ORGANIZACJI POŻYT-} KU PUBLICZNEGO w okresie sprawozdawczym (realizacja celów statutowych), w tym informacja o działalności wspieranej przez administrację publiczną w okresie sprawozdawczym.

W roku 2015 Fundacja by realizować swoje cele statutowe podjęła się wykonania następujących zadań: 
1. „UCHRONIĆ OD ZAPOMNIENIA. Edycja 2015-2017”. Całkowity koszt: 102 540,00 zł dotacja: Gminy Miasta Torun: 61 000,00 zł, środki własne Fundacji: 33 380,00 zł, praca wolontariuszy: 8160,00 zł (+praca społeczna nieujęta w kosztorysie zadania):

- zgromadzono materiały aktowe do 79 nowych teczek osobowych (55 - Archiwum Pomorskie; 24 - archiwum WSK). Łącznie na zbiory fundacji składają się 7202 teczki osobowe (A. WSK - 4313, A. Pom. - 2654, A. Zagrody - bez zmian, tj. 235);

- opracowano i uporządkowano w celu zdigitalizowania 2815 teczek osobowych;

- zgromadzono 59 egzemplarzy czasopism i 95 egzemplarzy książek tematycznie związanych z II wojną światową. 154 tytuły wydano jako dublety do bibliotek szkolnych oraz rozprowadzono w trakcie kiermaszów z przeznaczeniem dochodu na realizację celów statutowych. Łącznie zbiory Biblioteki Fundacji liczą 5806 egzemplarzy wydawnictw zwartych i 846 egzemplarzy wydawnictw ciągłych, co łącznie stanowi 6652 publikacje;

- indeksując akta składające się na zbiory fundacji oraz literaturę przedmiotu, sporządzono ok. 1350 kart rzeczowych (tzw. informacyjnych), do katalogów rzeczowych działu zbiorów: A. WSK włączono ok. 750 kart, A. Pomorskie -600;

- przeprowadzono 9 kwerend pełnych (A. Pom. - 9; A. WSK - 0; Biblioteka - 0) i kilkadziesiąt kwerend wstępnych, które wykonano na podstawie zapytań listownych (głównie e-mailowych) i telefonicznych;

- zbiory udostępniono 95 razy (A. Pom.- 43, A. WSK - 9, Muzealia, wystawy, systemy wystawiennicze - 12, Biblioteka - 31 osób/ 250 wypożyczeń).

2. „PRAWDZIWE HISTORIE”. Prelekcje i warsztaty historyczne dla dzieci i młodzieży. Całkowity koszt: 17 860,00 zł; dotacje: Zarząd Województwa Kujawsko-Pomorskiego: 9000,00 zł; FBZ WBK: 6000,00; środki własne Fundacji - 1420,00; praca wolontariuszy: 1440,00 zł.

W ramach realizacji projektu przeprowadzono 39 prelekcji i warsztatów tak w siedzibie Fundacji, jak i w toruńskich szkołach oraz poza Toruniem, m.in.: w Aleksandrowie Kujawskim, Chełmży, Kikole, Nakle nad Notecią, Solcu Kujawskim i Włocławku. Oprócz prelekcji i warsztatów realizowanych w ramach ww. projektu pracownicy Fundacji wygłaszają prelekcje i prowadzą warsztaty we współpracy z Klubami Grota, działającymi przy IPN. Najczęściej przedstawiciele fundacji są zapraszani przez łódzkie Kluby (kier. Antoni Galiński) z wykładami do szkół, ale i więzień. Łącznie w prelekcjach i warsztatach wzięło udział ponad 2800 osób.

3. „ARCHIWUM I MUZEUM POMORSKIE AK ORAZ WOJSKOWEJ SŁUŻBY POLEK ON-LINE". Całkowity koszt: 602 000,00; w roku sprawozdawczym wydatkowano: 138 034,10 zł, łącznie w latach 2012-2014 wydatkowano na realizację projektu 432 386,24 zł. Ministerstwo Nauki i Szkolnictwa Wyższego; kierownik projektu: prof. Jan Sziling, koordynator: dr K. Minczykowska. 
W ramach realizacji projektu w roku sprawozdawczym wykonano 72439 skanów z akt osobowych. Udostępniono on-line za pomocą www.kpbc.pl 590 teczek osobowych z działu zbiorów: "Archiwum Pomorskie”. W procesie digitalizacji w 2015 r. uczestniczyło: 14 osób (w tym 13 pracowników i 1 wolontariusz).

4. KADRY Z ŻYCIA CICHOCIEMNEJ. MURAL POŚWIĘCONY GENERAŁ ELŻBIETY ZAWACKIEJ I WYKONANY Z OKAZJI 25-LECIA FUNDACJI. Całkowity koszt 23 373,68 zł; dotacja Muzeum Historii Polski: 20 000,00 zł; środki własne Fundacji: 3373,68 zł.

Mural wykonał art. Marcin Grzęzlikowski (pseudo art. Andrzej po prostu), koordynacja: Agnieszka Łuczywek; lokalizacja: Torun, ul. Gagarina 136-138, ściana wieżowca, w którym mieszkała Elżbieta Zawacka.

\section{PRACE ARCHEOLOGICZNE I KONSERWATORSKIE}

1) Prace konserwatorskie artefaktów z Bykowni (Ukraina) dla Muzeum Katyńskiego. Całkowity koszt: 72 643,00 zl. Instytucja zamawiająca i finansująca: Rada Ochrony Pamięci Walk i Męczeństwa, Kierownik projektu dr Dominika Siemińska, konsultacja naukowa prof. Andrzej Kola

2) Prace archeologiczne na zamówienie Sądu Rejonowego w Toruniu, koszt: 11 500,00 zł, całość pokryta ze środków zamawiającego; kierownik badań: dr Dominika Siemińska.

\section{DZIAŁALNOŚĆ WYDAWNICZA}

1) Relacje członków konspiracji pomorskiej, pod red. Elżbiety Kwiatkowskiej-Dybaś.

Druk publikacji. Całkowity koszt: 5070,00 zł, dotacja Gminy Miasta Torun: 3000,00 zł; środki własne Fundacji: 2070,00 zł.

2) Akcja Burza. Materiały XXIV sesji fundacji w dniu 18 listopada 2014 r., pod red. K. Minczykowskiej i J. Szilinga.

Przygotowalnia i druk; nakład 300 egz. Po wyczerpaniu nakładu Fundacja udostępni pracę on-line. Całkowity koszt: 10 610,00 zł, dotacja Gminy Miasta Toruń: 5000,00 zł; dotacja UDSKiOR: 4000,00; środki własne Fundacji: 1610,00 zł.

3) Biuletyn Fundacji Generał Elżbiety Zawackiej, R. XXVII: 2015.

Nakład 1500 egz. (łącznie), Biuletyn jest bezpłatnie rozprowadzany, jest też do-stępny on-line. Całkowity koszt: 8400,00 zł, dotacja Gminy Miasta Torun: 5000,00 zł, środki własne Fundacji: 2800,00 zł, praca społeczna - 600,00 zł.

W 2015 r. Biuletyn Fundacji otrzymał 3 pkt (miał 1 pkt) w ocenie czasopism dokonywanej przez MNiSW (Lista B). 
7. KONFERENCJA NAUKOWA „KATYŃ-CHARKÓW-TWER-BYKOWNIA. W 75. ROCZNICĘ ZBRODNI KATYŃSKIEJ”, Toruń 14.04.2015 r.

Całkowity koszt: 30 563,80 zł, dotacja Gminy Miasta Torun: 6000,00 zł; dotacja UDSKiOR: 9000,00; środki własne: 12 413,79 zł; praca wolontariuszy: 3150,00 zł. Nadzór merytoryczny nad konferencją mieli: prof. Andrzej Kola i Jan Sziling, koordynacja: dr Katarzyna Minczykowska, kurator wystawy: dr Dominika Siemińska i dr hab. Sylwia Grochowina.

W konferencji wzięło udział ok. 250 osób, swoje referaty (+prezentacje) zaprezentowało 9 prelegentów (w tym 8 z Polski, 1 jeden z Ukrainy). Materiały z konferencji zostaną opublikowane po pozyskaniu na nie środków. Konferencji towarzyszyła wystawa artefaktów z grobów katyńskich oraz zdjęć dot. zbrodni katyńskiej.

8. I KONGRES HISTORYKÓW KONSPIRACJI NIEPODLEGŁOŚCIOWEJ: 25 lat niezależnych badań nad konspiracją niepodległościową 1939-1945. Ludzie, instytucje, wydarzenia, Torun 12-13.11.2015 r.

Współorganizatorzy: Instytut Historii i Archiwistyki UMK, Instytut Pamięci Narodowej oraz Muzeum II Wojny Światowej w Gdańsku.

Całkowity koszt: 66 000,00 zl, dotacja Gminy Miasta Toruń: 15 000,00 zł; środki własne: 5600,00 zł; praca wolontariuszy: 4500,00 zł; wkład współorganizatorów: Muzeum II Wojny Światowej: 21 000,00; IPN: 19 900,00.

Zebrani goście (ok. 300 osób) wysłuchali 20 referatów nt. stanu badań dotyczących poszczególnych zagadnień związanych z konspiracją polską 1939-1945 (np. działalność konspiracyjna w poszczególnych dzielnicach Polski) oraz mieli okazję zapoznać się z ofertą edukacyjną instytucji, takich jak: IPN, Muzeum Powstania Warszawskiego czy Muzeum AK w Krakowie. Ponadto z bardzo dużym zainteresowaniem spotkało się prowadzone przez Oferenta w trakcie Kongresu 16 warsztatów dla dzieci i młodzieży, w których uczestniczyło 300 osób.

\section{PATRONATY, UROCZYSTOŚCI, GREMIA DORADCZE}

1) W ramach współpracy ze szkołami Fundacja patronowała, przekazywała nagrody książkowe, a pracownicy Fundacji brali udział w jury bądź udostępniali siedzibę Fundacji na uroczystości wręczenia nagród następujących konkursów szkolnych:

- „Oni tworzyli naszą historię” Konkurs historyczny im. gen. Elżbiety Zawackiej (organizator: Marszałek Województwa Kujawsko-Pomorskiego);

- III Wojewódzki Konkurs Katarzynkowy, Toruń 11.12.2015 r.

2) Fundacja też współorganizowała

- obchody 106. rocznicy urodzin gen. Elżbiety Zawackiej (tu też wystawienie monodramu spektaklu „Elizabeth Watson - cichociemna” w Toruniu);

- konkurs wiedzy o gen. Elżbiecie Zawackiej (wspólnie z ZHP Toruń), Toruń 21.03.2015 r.; 
- uroczystości z okazji 69. rocznicy wybuchu powstania warszawskiego, Toruń 1.08.2015 r. (wspólnie z UM Torun, Urzędem Marszałkowskim i Stowarzyszeniem: Muzeum Historyczno-Wojskowe w Toruniu);

- uroczystości z okazji Dnia Polskiego Państwa Podziemnego, Toruń 27.09.2015 r.

3) Przedstawiciele Fundacji brali też udział w następujących imprezach:

- Szkolenie: Jak skutecznie prowadzić archiwum społeczne, Warszawa 7-9.02.2015 r.;

- Konkurs szkolny „Kartka z pamiętnika małego powstańca”, Toruń czerwiec 2015 r., organizator: Gimnazjum nr 24 w Toruniu;

- Konferencja „Swojskość i obcość w regionie kujawsko-pomorskim”, Bydgoszcz 17.09.2015 r.;

- Forum Muzeów Martyrologicznych, Sztutowo wrzesień 2015 r.;

- XXXIV Zjazd Żołnierzy Kresowych, Międzyzdroje 5-9.10.2015 r.;

- I Kongres Archiwów Społecznych, Warszawa 24.10.2015 r.;

- Wieczór Pieśni Patriotycznych (organizator: Gimnazjum nr 2 im. Gen. Elżbiety Zawackiej), Toruń 19.11.2015 r.

4) Przedstawiciele Fundacji brali też udział w obradach gremiów doradczych:

- Rada Muzeum II Wojny Światowej (prezes Dorota Zawacka-Wakarecy);

- Wojewódzki Komitet Ochrony Pamięci Walk i Męczeństwa (dokumentalistka Elżbieta Skerska);

- Miejski Komitet Ochrony Pamięci Walk i Męczeństwa (prezes Dorota Zawacka-Wakarecy).

\section{DZIAŁALNOŚĆ SEKRETARIATU: GOŚCIE, KORESPONDENCJA}

1) W celu realizacji celów statutowych $\mathrm{z}$ sekretariatu Fundacji wyekspediowano tradycyjną pocztą 1746 przesyłek (listów i paczek). Zarejestrowano 436 listów, które wpłynęły do sekretariatu Fundacji za pośrednictwem poczty polskiej.

2) Na skrzynkę e-mail Fundacji wpłynęło 3643 e-maile od interesantów i współpracowników Fundacji. E-maili wysłanych ze skrzynki fundacyjnej zarejestrowano ok. 4500.

3) Sprzedano i rozdysponowano gratisowo 1101 książek (790 sprzedano; 311 rozdysponowano bezpłatnie), rozdysponowano bezpłatnie 1845 egz. Biuletynu Fundacji.

Fundację odwiedziło ok. 800 osób (zwiedzający, goście Kongresu, uczestnicy prelekcji). 


\section{DZIAŁALNOŚĆ GOSPODARCZA}

Fundacja nie prowadzi działalności gospodarczej.

\section{KORZYSTANIE Z UPRAWNIEŃ W OKRESIE SPRAWOZDAW- CZYM}

a) Zwolnienia z podatków: działalność Fundacji nie podlega opodatkowaniu; zwolniona z opłat podatkowych od nieruchomości.

b) Zwolnienia z opłat sądowych: zwolniona.

c) Korzystanie z uprawnień do nabywania, użytkowania wieczystego na szczególnych zasadach nieruchomości Skarbu Państwa: Fundacja od 2006 r. korzysta z użytkowania wieczystego budynku, który jest siedzibą Fundacji.

\section{PODSUMOWANIE}

Realizowanie statutowych zadań Fundacji w ciągu całego ubiegłego roku wiązało się z wielkim zaangażowaniem jej pracowników. Zarząd Fundacji dziękuje Im serdecznie.

Zarząd Fundacji pragnie podkreślić, że w swej działalności spotykał się z życzliwością i poparciem władz i instytucji, którym należy się szczególne podziękowanie.

Dziękujemy Urzędowi Miasta Torunia z panem Prezydentem Michałem Zaleskim oraz Radzie Miejskiej Torunia z jej przewodniczącym panem dr. hab. Marcinem Czyżniewskim.

Dziękujemy Instytutowi Pamięci Narodowej, Instytutowi Historii i Archiwistyki UMK, Muzeum II Wojny Światowej w Gdańsku, Samorządowi Województwa Kujawsko-Pomorskiego oraz Zarządowi Fundacji Banku Zachodniego WBK i dyrektorowi tego banku w Toruniu.

Dziękujemy wszystkim instytucjom i ofiarodawcom indywidualnym, których pomoc i dotacje umożliwiły naszą działalność.

Sekretarz Zarządu

Donote knomp
Dorota Kromp
Prezes Zarządu

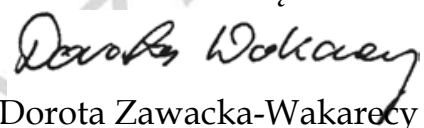

Wiceprezes Zarządu

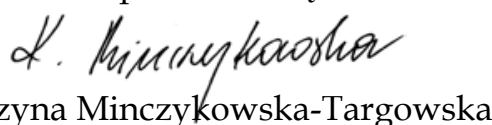

Katarzyna Minczykowska-Targowska 